\title{
Towards the new frontier
}

\author{
Fiona Godlee editor in chief
}

The BMJ

Anyone working in healthcare will be feeling the pressure of rising demand and limited resources. Being asked to rethink how you do things may be the last straw. But this is what the sustainability and transformation partnerships (STPs) are asking clinicians in England to do. So far the outcome has been mixed at best. As Jennifer Richardson reports this week (doi:10.1136/ bmj.j5130), the prevailing view among hospital doctors is unengaged and unenthusiastic, with many who responded to a recent survey doubting the motives behind STPs and their likelihood of success.

But several commentators say that doctors must find the time to get involved. "The direction and destination is the right one and STPs are the only game in town," says Andrew Goddard of the Royal College of Physicians. "We as clinicians need to get playing that game ... Without us it is all going to go horribly wrong."

This was a key message at the Leaders in Healthcare conference in Liverpool last week (www.leadersinhealthcare.com). Speaking more broadly about the past, present, and future of the NHS, England's national medical director, Bruce Keogh, charged doctors with using their "huge influence" effectively. "Anybody who has the title 'consultant' is de facto a senior manager in their organisation, and we cannot abrogate responsibility," he said.
Jessica Watson and colleagues (doi:10.1136/bmj.j4944) see STPs as one route for clinicians to increase the value of care throughout the entire system. As they describe it, "value based healthcare" is the new frontier beyond evidence based medicine. Crucially, they believe it offers hope for more rational, clinically led decision making in a world of increasing demand and shrinking resources. In partnership with patients, clinicians are, or should be, responsible for the allocation of resources, whether to the individual, within an organisation, or across a population, they say.

Delivering higher value healthcare means doing less of low value and more of high value, Watson and colleagues say. On their evidence based list of things to stop are health checks, unnecessary appointments, and polypharmacy. Resources freed up could be shifted to social prescribing, integration, and continuity of care, among other things. The aim should be to tackle unwarranted variation, to decrease waste, and to "demedicalise" care whenever possible, they say.

As for how much we spend on healthcare, you may well agree with David Oliver's call for "cold hard cash to prevent the service crashing around our ears" (doi:10.1136/bmj.j4800). But while that debate continues, let's also look hard at the value of what we do. 